\title{
Prática docente: Concepções sobre o uso de ambientes educacionais baseados na Web
}

\author{
Eliane Maria Balcevicz Grotto* \\ Eduardo Adolfo Terrazzan **
}

RESUMO: A pesquisa toma por base a realidade da sociedade tecnológica atual que gera necessidade de mudanças nas diversas esferas educacionais. Esta realidade social sinaliza para a necessidade de se repensar as práticas pedagógicas. Diferentes modalidades de ensino-aprendizagem existentes trabalham associadas a diferentes meios de comunicação e, sem dúvida a Internet é um meio que cresce exponencialmente. Graças ao sistema de interface gráfica Web é possível ter acesso a ambientes de ensino-aprendizagem interativos. Com base nesses pressupostos o artigo faz uma breve reflexão do referencial teórico o qual fundamenta esta pesquisa em andamento, que tem como objetivo analisar a formação dos professores de Educação Básica quanto o uso de ambientes educacionais baseados na Web e que fatores consideram como indicativo para o uso desse recurso.

\section{PALAVRAS CHAVES: Educação - Internet - Prática pedagógica} on web

Teacher practice: Conception about the uses of educationls surroundings based

ABSTRACT: The research hás for base the reality of modern technologia society which begets necessity of changes in several spheres educationals. This social reality signs for the necessity modarethink the pedagogical practices. Different modalities of teaching-learning works associated to the different ways of communication and without doubts, the Internet is a way that increases uncommon thanks to the web graph interface system in is possible to acess the teaching-learning interative surroundings. With base in these estimated the article makes a brief reflection of the theoretical referencial which bases this research in progress that has as objective to analyze the formation of the teachers of Basic Education how much the based educational environment based in Web and which factors consider as indicative for the use of this resource.

KEY-WORDS: Education - Internet - Pedagogical Practice

As transformações sociais, econômicas e tecnológicas impõem novas formas de ensinar e aprender. As tecnologias da informação vêm sendo crescentemente incorporado ao processo ensino - aprendizagem como recurso de mediação entre o indivíduo e o conhecimento. Enquanto a sociedade como um todo criou novas formas, ou mídias, de armazenar/transmitir as informações, a escola, apesar dessas iniciativas, permanece impassível diante das transformações da realidade que a tecnologia está provocando.

Como anteriormente citado este artigo faz uma breve reflexão do referencial teórico o qual fundamenta esta pesquisa em andamento. A mesma esta sendo desenvolvida pela mestranda do Programa de Pós-Graduação - Mestrado em Educação

\footnotetext{
Mestranda do PPGE/UFSM - Aluna PEC/UFRGS - Professora URI/F.W.

** Orientador Prof. Dr. Do centro de Educação - PPGE da UFSM/RS 
na Universidade Federal de Santa Maria - RS. Tendo como objetivo analisar a formação dos professores de Educação Básica quanto o uso de ambientes educacionais baseados na Web e que fatores consideram como indicativo para o uso desse recurso.

Para Loing (1998), a introdução das NTICs na educação deve ser acompanhada de uma reflexão sobre a necessidade de uma mudança na concepção de aprendizagem vigente na maioria das escolas atualmente. Tal reflexão deverá levar a uma mudança na própria estrutura do ensino, que estimule a iniciativa e criatividade, preocupando-se menos com o cumprimento do currículo. Para isso, torna-se necessário preparar o professor para assumir uma nova responsabilidade como mediador do processo de aquisição de conhecimento e do desenvolvimento da criatividade de seus alunos. Nessa ótica, a tecnologia pode ser um recurso valioso, facilitando esta intermediação e um atendimento mais individualizado, ajudando o aluno a se apropriar do conhecimento. Os professores assumem uma nova responsabilidade e um papel central como mediadores do processo de apropriação, construção e elaboração de conhecimentos, assim as NTICs, podem se tornar poderosos auxiliares dos professores nesse novo papel.Como viabilizar uma proposta pedagógica que desestruture as práticas hegemônicas dos professores, como criar condições para que um professor acostumado a trabalhar dentro de um modelo que enfatiza a transmissão de conhecimento, passe a trabalhar criativamente, criando um ambiente que incentive a criatividade do aluno, rico em aprendizagem, mediado pelas NTICs ?

Para que os professores possam refletir sobre essas questões, apropriar, construir novos conhecimentos, transferir, aplicá-los e redimensionar à sua prática, Duffy e Jonassem (1991), preconizam que é importante que eles aprendam significativamente, que trabalhem com problemas reais em contextos reais. Assim, qualquer projeto de capacitação de professores no uso das novas tecnologias como recurso pedagógico, que leve em conta as considerações feitas acima, têm que ter como objetivo fundamental a realização da tarefa global em toda complexidade. Para tal realização, o professor, na condição de aprendiz, tem que assumir um papel importante na gerência e controle da sua aprendizagem. Isso pode acontecer se for propiciado ao mesmo usar seus conhecimentos, na resolução de situações-problema, através de atividades cognitivas. Para que o professor possa abandonar sua prática tradicional e dar margens à criatividade em sua prática pedagógica, é necessário que ele possa, nos cursos de capacitação, vivenciá-la, criar sua prática, experimentar e errar. Desta forma é necessária que os cursos de capacitação, sejam verdadeira oficina de aprendizagem, um ambiente rico que incentive a criatividade dos professores/aprendizes e não cursos que oferecem modelos de atuação, verdadeiras receitas de atividades.

Segundo Dewey, ambientes de aprendizagens são sistemas de ensino e aprendizagens integrados e abrangentes capazes de promover o engajamento dos aprendizes.Numa perspectiva construtivista-interacionista, as atividades devem ser centralizadas no aprendiz e os temas inter-relacionados e contextualizados em ambientes onde os mesmos possam ser construtores de suas próprias estruturas intelectuais.Para se criar um ambiente construtivista alguns pressupostos básicos da teoria de Piaget devem ser levados em conta; a primeira exigência é que o ambiente permita uma interação muito grande do aluno/aprendiz com o objeto de estudo. Essa interação não significa apenas o apertar de teclas ou o escolher entre opções de navegação. A interação deve passar além disso integrando o objeto de estudo à realidade do sujeito, dentro de suas condições de forma a estimulá-lo e desafiá-lo, mas ao mesmo tempo permitindo que as novas situações criadas possam ser adaptadas às estruturas cognitivas existentes, propiciando o seu desenvolvimento.

Muitas teorias sobre aprendizagem parecem concordar com a idéia de que essa é um processo de construção de relações, em que o aprendiz, como ser ativo, na interação

\footnotetext{
$2 \longrightarrow$ V.1 N², Setembro, 2003
} 
com o mundo, é o responsável (pela direção e significado do aprendido). O processo de aprendizagem, feita estas considerações, se daria em virtude do fazer e do refletir sobre o fazer, sendo fundamental no professor/aprendiz o "saber", o "saber fazer".

Assim a introdução das novas tecnologias na educação deve ser acompanhada de considerações sobre as inevitáveis mudanças a serem introduzidas na maneira de ensinar e aprender, repensar o papel do professor, e a reestruturação da escola para esta nova realidade. As novas tecnologias de informação e comunicação encontra - se em diferentes lugares e espaços e não podem passar por despercebidas. Todos os indicadores mostram que estamos no limiar da nova era da comunicação. O crescimento da Internet é exponencial e não se pode desprezar o seu uso para fins educacionais, bem como o redimesionamento do papel do professor neste percurso. É necessária uma capacitação dos professores, que leve em considerações as questões apontadas acima e a implantação de uma cultura que incentive a realização de projetos de aprendizagem.

Se analisarmos o comportamento histórico do processo ensino-aprendizagem temos no passado o professor como centro e único detentor do conhecimento e o aluno simples receptor. No presente considera-se as interações entre professor/aluno mas o professor continua a ser a única fonte do conhecimento e experiência. Como desafio para o futuro, Branson apresenta um modelo centrado na tecnologia dos sistemas especialistas e bases de conhecimento onde professor e alunos interagem entre si e com a base. Neste caso o sistema educacional centra-se na tecnologia com uma capacidade muito grande de armazenamento de informações. Os desenvolvimentos de tais sistemas demandam tempo, recursos financeiro e pessoal capacitado o que torna este modelo um grande desafio para o futuro.

Costa e Souza(1992) propõe uma ação baseada em redes de informações sugerindo que o professor contribua apoiando os trabalhos, permitindo que o contato com as novas tecnologias seja mais proveitoso. Aqui o professor será o agente estimulador, o desafiador, facilitador para os alunos quando buscarem a rede, para que os objetivos não se percam antes de serem atingidos. Os alunos por sua vez gerenciam o ritmo de aprendizagem, interagem com os pares e trabalham em conjunto para alcançar objetivos comuns caracterizando o aprendizado cooperativo.

A aprendizagem colaborativa torna-se muito mais interessante quando os alunos podem trabalhar com alunos de outras culturas, ampliando dessa maneira o seu conhecimento.Numa perspectiva educacional, centrada na utilização da NTICs como elemento didático, os trabalhos seguem uma proposta pedagógica mais ampla, responsável pela motivação e preparação dos professores, apoiando a educação formal, partilhando com a rede, transmissão, geração e transformação dos conhecimentos.É mister que os professores tenham consciência que o uso das NTICs na educação devem ter como objetivo mediar a construção do processo de conceituação dos alunos, buscando a promoção da aprendizagem e desenvolvendo habilidades importantes para que eles participem da sociedade do conhecimento e, não simplesmente facilitando o seu processo de ensino e de aprendizagem.

Para que o professor possa assumir o papel de mediador entre o conhecimento organizado e a (re)construção do conhecimento pelo aluno, com a mediação instrumental das NTICs, sua formação e capacitação continuada deve passar pela (re)construção de um saber pedagógico baseado na atividade e não apenas em um discurso psicologizante, desempenhando um papel central como agente fundamental dessa mudança.

No entanto, com a inserção das novas tecnologias nas práticas pedagógicas a educação presencial ganha uma nova dimensão com novas possibilidades e desafios, o que nos induz a repensar as formas de aprender e de ensinar. Na rede há uma grande diversidade de informações disponíveis e organizadas de várias maneiras, permitindo 
seu acesso tanto no sentido da abrangência (favorecendo a multiplicidade de relações) como no aprofundamento (privilegiando as particularidades e detalhes). Mas, em termos de aprendizagem, ter acesso e adquirir informação é a mesma coisa que ter conhecimento?

Equivocadamente, muitas vezes, a informação e o conhecimento são vistos e tratados como sinônimos, mas são conceitos distintos. Reconhecer esta distinção, bem como a inter-relação que existe entre informação e conhecimento, é extremamente importante para a prática do professor e a aprendizagem do aluno. Na sala de aula, muitas vezes, o professor tem a intenção de transmitir conhecimento, mas $o$ conhecimento não se transmite. O professor certamente tem o conhecimento, mas aquilo que ele transmite para o aluno é informação, que pode adquirir significado para o aluno e ser por ele transformada em conhecimento. A informação, tanto a transmitida pelo professor como a encontrada na Internet ou, ainda, em outros meios, pode inclusive ter uma organização pedagógica intencional, mas isto não garante que o aluno construa o conhecimento.

Uma determinada informação precisa ser interpretada e reelaborada pelo aluno. Este processo de interpretar, ou seja, de dar sentido à informação requer ações do conhecimento. Transformar a informação em conhecimento não é algo que acontece de forma instantânea. É preciso que as informações sejam trabalhadas conjuntamente em várias situações de aprendizagem, de modo que o aluno possa estabelecer relações, comparar, diferenciar, experimentar, analisar, atribuir significado e sistematizar os conceitos envolvidos num processo contínuo de (re)construção do conhecimento (Piaget, 1977).

As atividades que privilegiam a autoria do aluno e o processo de (re)elaboração de algo que lhe seja significativo possibilitam que este aluno possa interpretar as informações, articulando-as com seu universo de representação do conhecimento.As questões que se colocam são: Como propiciar condições para que o aluno possa vivenciar estas situações de aprendizagem no contexto de educação virtual? A informação veiculada através de ambientes educacionais baseados na Web pode ser trabalhada no sentido de propiciar ao aluno a construção de conhecimento?

Depende, sem dúvida, da abordagem educacional que norteia a ação do professor. Numa abordagem do tipo broadcast que, segundo Valente (1999), utiliza os recursos tecnológicos para "entregar" informação ao aluno, provavelmente é esperado que isto seja suficiente para que o aluno aprenda. Nesta situação, o aluno aprende a reproduzir as informações recebidas, mas será que ele aprende a transformá-las em conhecimento? Por outro lado, o uso da rede voltado apenas para disponibilizar informações, mesmo que tenham um formato inovador próprio do ambiente Web, continua sendo uma forma de sub-utilização dos recursos da Internet (Prado \& Marins, 2001).

No entanto, existem propostas de ambientes baseadas em pressupostos que enfatizam o processo de construção do conhecimento por meio das interações e do trabalho colaborativo. Sob este enfoque, a abordagem de educação via telemática denominada por Valente (1999) de o estar junto virtual integra o uso dos vários recursos do ambiente virtual para criar situações de aprendizagem que possam favorecer o aluno a transformar as informações em conhecimento. Nestas situações de aprendizagem, o aluno pode vivenciar um processo de ação reflexiva, de articulação com a prática, de depuração e de (re)construção do conhecimento.

Os ambientes baseados na Web de suporte para o processo de ensino e aprendizagem são constituídos por um conjunto de ferramentas que possibilitam a organização, o gerenciamento e as várias formas de interação. Cada ferramenta tem suas particularidades, pois foram criadas para determinados fins. Existem aquelas 
ferramentas apropriadas para disponibilização de materiais relativos a textos de conteúdo,atividades, informativo, leituras, etc. Entre outras, existem aquelas ferramentas que viabilizam a interação entre os usuários, tais como, Chat, Fórum de Discussão, Correio Eletrônico, Portfólio. O uso que se faz destas ferramentas depende do objetivo do professor e das características dos participantes (necessidades e/ou interesses). Embora estas ferramentas sejam de extrema importância, cabe ao professor dar vida, ou seja, dinamizar o seu uso com os alunos. Geralmente, estas ferramentas, do ponto de vista técnico, são simples de serem manipuladas, mas as possibilidades e implicações pedagógicas dependem da (re)significação que o professor pode fazer no contexto de sua prática.Assim, aborda-se algumas destas possibilidades e implicações pedagógicas em relação às ferramentas Fórum de Discussão, Portfólio e Chat.

A dinâmica e o gerenciamento do Fórum de Discussão, com vistas a instigar a participação e a interação entre os alunos, demanda do professor atentar para alguns aspectos, como por exemplo: escolher um tema que seja pertinente para os participantes; elaborar questões abertas e provocativas e que possam ser facilmente interpretadas pelos alunos; utilizar uma linguagem clara, não muito extensa nem demasiadamente acadêmica; (re)-alimentar as discussões de forma equilibrada, para que os participantes encontrem espaço para interagir entre si; cuidar para que as discussões possam ampliar as idéias, podendo com isto gerar subtemas, mas sem perder o foco, para que não ocorra uma pulverização de questões desarticuladas.

Os dois últimos itens são mais complexos, pois dependem da inter-relação de vários fatores que surgem da situação. Um dos caminhos é o professor observar as sinalizações que os alunos expressam nos vários espaços do ambiente do curso. No entanto, isto requer do professor flexibilidade $e$ responsabilidade para contemplar as questões emergentes e inusitadas, de modo que possam ser integradas aos propósitos do curso. "O mais importante é a credibilidade do professor, sua capacidade de estabelecer laços de empatia, de afeto, de colaboração, de incentivo, de manter o equilíbrio entre flexibilidade e organização" (Moran, 2000:55).

De fato, tanto no Fórum de Discussão como em outras ferramentas de interação, as relações interpessoais e afetivas são fortemente evidenciadas quando as atitudes são carregadas de valores como respeito, reciprocidade e confiança entre os participantes.

O compartilhamento, esta possibilidade do contexto virtual, é extremamente importante, pois é na troca de experiências, reflexões e sentimentos entre os alunos que se fortalece o trabalho coletivo e colaborativo. As múltiplas interações que acontecem de forma diversificada potencializam a construção da rede humana de aprendizagem. Esta rede de aprendizagem requer do aluno o exercício da interpretação das idéias do outro, explicitada via escrita, bem como a sua (re)organização de pensamento para revelar-se para o outro, também por meio da escrita. Neste processo participam alunos com diferentes experiências e maneiras de expressar o pensamento. $O$ processo de um aprender com $o$ outro não é uma atividade puramente intelectual e impessoal. O importante nesta interação é a constante busca de compreensão do outro e de si mesmo, de querer comunicar-se, de compartilhar e de crescer.

Ferramenta Portfólio (individual e/ou em grupo) representa um espaço importante, porque o aluno e/ou um grupo de alunos pode $(\mathrm{m})$ compartilhar com os colegas e/ou professor suas atividades/projetos durante o processo de elaboração. Isto significa que a ênfase da aprendizagem está centrada no processo e, portanto, na possibilidade de o aluno poder dar e receber feedback sobre aquilo que está produzindo individualmente e/ou em grupo. A diversidade de olhares enriquece o feedback do aluno, provocando com isso novas relações e a busca de novas compreensões (Prado \& Valente, 2002).

O professor nesta abordagem atua como mediador e desenvolve também ações investigativas. Ele analisa, ao mesmo tempo, o processo de aprendizagem do aluno - que se expressa nos vários espaços do ambiente virtual - e, a sua própria prática pedagógica. Esta forma de atuação permite ao professor colocar-se como parceiro dos alunos, respeitando seu estilo de trabalho, a sua autoria e as estratégias adotadas (Almeida, 2001). O papel do professor, segundo, Perrenoud (2000), concentra-se "na criação, na gestão e na regulação das situações de aprendizagem" (p.139). 
Neste sentido, as ações do professor devem estar pautadas por uma pedagogia relacional que contempla a complexidade que a educação a distância requer. Nesta concepção, não existem soluções prontas, estratégias e modelos previamente definidos: existem princípios, intenções e o compromisso pedagógico com o desenvolvimento cognitivo, afetivo, social e humano dos alunos, que orientam a (re)construção destas estratégias na e para a ação do professor.

O chat permite uma conversa em tempo-real entre os participantes. A sua utilização pode ser diversificada, por exemplo, pode ser interessante ter um chat como um momento do brain-storm entre os participantes (Masetto, 2000). Este tipo de encontro on-line pode caracterizar-se como um momento criativo, construído coletivamente para gerar novas idéias e temas a serem estudados e aprofundados. No chat, a explicitação dos alunos é feita de forma espontânea, uma vez que este recurso exige uma escrita rápida. Diferentemente dos demais recursos (Fórum de Discussão, Portfólio, Correio Eletrônico), em que acontecem os encontros off-line, a explicitação dos alunos geralmente é feita de forma mais elaborada. São duas maneiras diferentes de expressar o pensamento, as quais podem ser vistas e interpretadas de forma complementar.

Um outro aspecto que precisa ser considerado é o número de participantes em um chat. Interpretar as idéias de várias pessoas ao mesmo tempo não é trivial, depende daquilo que se espera de um chat para criar estratégias apropriadas. Estas características da ferramenta favorecem muito mais os participantes a estarem extravasando algo que os esteja preocupando naquele momento (dúvidas, questionamentos, sentimentos) do que discutir questões mais complexas de forma articulada com as idéias dos colegas.

Uma possibilidade é utilizar o chat também após a sua realização. O registro da conversa on-line pode ser tratado como um texto "desorganizado" a ser trabalhado tanto pelo professor como pelos alunos, categorizando as questões emergentes para serem discutidas, por exemplo, no espaço do Fórum de Discussão. De igual maneira, estas questões podem estar relacionadas às atividades/projetos compartilhados no Portfólio. Além destas interligações entre as ferramentas de interação, existem outras que podem estar diretamente relacionadas: são aquelas que organizam a disponibilização de materiais de leituras sobre conteúdos específicos.E assim... Interligando as várias ferramentas do ambiente virtual e integrando saberes - alunos e professor - vão construindo coletivamente a rede humana de aprendizagem.

A metodologia utilizada nesta pesquisa em andamento conta com um número de dez professores de três escolas de Educação Básica, duas privadas e uma pública. Os instrumentos para coleta de dados podem ser classificados na seguinte ordem: primeira fase se refere a entrevista com os professores a fim de identificar os fatores atribuídos para o uso desse recurso, concepções e contribuições do ponto de vista pedagógico e de aprendizagem; segunda fase consiste na observação da prática do professor em utilizar os ambientes educacionais disponíveis na Web. Essa técnica possibilitará fazer uma análise tanto de indicativos analítico-informáticos como de indicativos analíticoeducativos que envolvem os ambientes e a prática pedagógica. A análise documental (planos de aula) fará parte de um terceiro momento da pesquisa com o intuito de verificar se as atividades com ambientes on-line fazem parte de um planejamento/projetos. Quanto aos resultados conclusivos, estes não podem ser explicitados, pois esta pesquisa encontra-se em fase de desenvolvimento, entretanto, preliminarmente alguns dados podem ser constatado quanto o uso de ambientes educacionais baseados na Web: o uso de ambientes on-line pelos professores do Ensino Fundamental e Médio em sua prática pedagógica é quase enexistentes. São vários os fatores que implicam o não uso desse recurso, um deles se refere à falta de referencial teórico para dar suporte a essa prática. Em relação aos sujeitos selecionados para essa 
pesquisa é importante ressaltar que os mesmos revelam ter conhecimento da informática na educação devido estudos/pesquisas desenvolvidas durante a graduação, especialização e/ou mestrado, envolvendo a informática e a educação. Portanto, como dados preliminares à formação do professor para o uso das novas tecnologias de Informações e Comunicação se considera frágil. A Internet como qualquer outra tecnologia digital é constituída de duas vertentes - a informativa e a construtiva - sendo que há uma predominância do lado informativo na concepção de suas aplicações. Quanto aos fatores os professores apontam para o uso dos ambientes indicadores como: estimula diferentes formas de aprendizagem (imagens/sons/vídeo e animações); potencialidade informativa e comunicacional aliada ao entretenimento; interatividade; design dos ambientes(estimula/ motiva/ seduz o aluno para a aprendizagem).

\section{REFERÊNCIAS BIBLIOGRAFICAS}

ALMEIDA, M. E. B. (2001). Formando professores para atuar em ambientes virtuais de aprendizagem. In: Almeida, F. J. (coord.). Projeto Nave. Educação a distância. Formação de professores em ambientes virtuais e colaborativos de aprendizagem. São Paulo: s.n.

BELLONI, M.L.(1998). Tecnologia e formação de professores: Rumo a uma pedagogia pós-moderna. Educação e Sociedade. № 19. 143-162.

BATTRO, A. M.DENHAM, P. J.(1997). La educación digital. Buenos Aires: Emecé Editores.

BERNHARD, Paulette. La formación en el uso de la información: una ventaja en la enseñanza superior. Situacíon actual. Disponível em: http://www.adelf.ca./revue/XXVII-2/resumes.html Acesso em: 15 dez.2002.

BIANCHETTI, Lucídio.(2001). Da chave de fenda ao laptop. Tecnologia digital e novas qualificações: desafios à educação. Florianópolis-SC-: Editora da UFSC

CASTELLS, M. (1999). A sociedade em rede. São Paulo: Paz e Terra.

COUTINHO, M. Teresa da Cunha.(1998). Psicologia da Educação: um estudo dos processos psicológicos de desenvolvimento e aprendizagenm humanos, voltados para a educação : ênfase na abordagem construtivista - 6. Ed. - Belo Horizonte, MG: Ed. Lê. Papirus.

CUNHA, Maria Izabel da.(1989). O bom professor e sua prática. São Paulo:

DEMO, Pedro.(1997). Conhecer e Aprender. Porto Alegre: Artes Médicas.

ESTRÁZZLAS, M. Interação e Cooperação em lista de discussão. Revista Informática na Educação: Teoria \& Prática. UFRGS: outubro, 199. P.81 - 86.

FAGUNDES, L.C. \& AXT, M.(1992).Comunicação via Rede Telemática: A construção de um saber partilhando com vistas a mudanças na prática educativa.Porto Alegre: Letras de Hoje. N.4.

HAMIT, Francis. Realidade virtual e a exploração do espaço cibernético. Rio de Janeiro: Berkeley, 1993. P. 372.

HEIDE, Ann e STILBORNE, Linda.(2000). Guia do professor para a Internet. Porto Alegre: ed 2, Artes Médicas Sul.

LÉVY, Pierre.(1998). A máquina universo: criação, cognição e cultura informática. Porto Alegre: Artmed. 
MARTON, Phelippe.Les technologies de Ì' information et de la communication et leur avenir en éducation. Disponível em: http://www.adelf.ca./revue/XXVII2/resumes.html Acesso em: 15 dez.2002.

MORAN, J. M. (2000). Ensino e aprendizagem inovadores com tecnologias audiovisuais e telemáticas. In: MORAN, J. M. \& MASETTO, M. T., \& BEHRENS, M. A. Novas Tecnologias e Mediação Pedagógica. Campinas (SP): Papirus. LEITE, D. \& MOROSINI, M.(1992) Universidade no Brasil: A idéia e a Prática. Revista Brasileira de Estudos Pedagógicos. 73 (174): 242-254. Brasília, maio/agosto.

LIBÂNEO, J.C. (1999).Adeus professor, adeus professora? Novas exigências educacionais e profissão docente. 3.ed. São Paulo: Cortez.

NOGUEIRA, A C. (1993). Multimídia na construção do conhecimento. Tecnologia Educacional. No 22, 39-41.

PASSOS. Ilma, Alencastro. A prática pedagógica do professor de didática. Campinas: Papirus, 1992.

PAPERT, Saymor.(1994).A máquina das crianças: repensando a escola na era da informática. 2 ed. Porto Alegre: Artes Médicas.

PERRENOUD, P. (2000). Dez Novas competências para ensinar. Porto Alegre: Artes Médica Sul.

PIAGET, Jean.(1990).Epistemologia genética. São Paulo: Martins Fontes. (1973).Estudos Sociológicos. Rio de Janeiro: Forense. . (1977). A tomada de consciência. São Paulo: Melhoramentos e Editora da Universidade de São Paulo.

PONTE, J.P. \& SERRAZINA, L. (1998). As novas tecnologias na formação inicial dos professores. Lisboa: DAPP do ME.

PONTE, J.P. da \& OLIVEIRA, Hélia \& VARANDAS, J.M. O contributo das tecnologias de informação e comunicação para o desenvolvimento e da identidade profissional. Disponível em: $\quad$ www.educ.fc.pt/docentes/jponte/curso-rio-claro-htm Acesso em: 10 de dez.2002.

SANCHO, J.M. Lição para usar tecnologia. Caderno Empregos e Educação para o trabalho. Jornal do Brasil, 20 de junho de 1999, p.1-2.

SANDHOLTZ, H. Judith; RIGSTAFF, Cathy \& DWYER, C. David.(1997). Ensinando com tecnologia: criando salas de aula centradas nos alunos.Porto Alegre: Artes Médicas.

SAMPAIO, Marisa Narcizo \& LEITE, Lígia Silva. (1999). Alfabetização Tecnológica do professor.Petrópolis - RJ: ed. Vozes.

SANTOS. Milton. Por uma outra globalização: do pensamento à consciência universal. Rio de Janeiro: Record, 2000.

STAHL, M. (1997). Formação de professores para uso das tecnologias de comunicação e informação. In: CANDAU(org). Magistério: construção cotidiana. Petrópolis: Vozes, p.292-317.

SETZER, Valdemar W. (2002). Meios eletrônicos e educação uma visão alternativa. São Paulo: ed. Escrituras.

STORT, Eliana V.R.(1993). Cultura, imaginação e conhecimento: a educação e formalização da experiência. Campinas - SP: Editora UNICAMP.

TAJRA, S.F. (1998). Informática na Educação: Novas ferramentas pedagógicas para o professor na atualidade. São Paulo. Érica. distribuiciones.

VERA, Antonio Bautista García.(1994).Las nuevas tecnologías en la capacitación docente. Madrid: Visor

VALENTE, José Armando $\left(1993^{\mathrm{a}}\right)$.Diferentes usos do computador na educacão. In: VALENTE, José Armando(Org.) Computadores e conhecimento: repensando a educação. Campinas: UNICAMP. 
. $\left(1998^{\mathrm{a}}\right)$. Formação de profissionais na área de informática em educação. In: Valente(org.) Computadores e conhecimento: repensando a educação. Campinas: UNICAMP/NIED, p. 139-164, $\left(1998^{\mathrm{a}}\right)$.

(1999). Diferentes abordagens de educação a distância. Coleção Série Informática na Educação - TV Escola, publicado no site: http://www.proinfo.gov.br 